\title{
Increased mucosal nitric oxide production in ulcerative colitis is mediated in part by the enteroglial-derived S100B protein
}

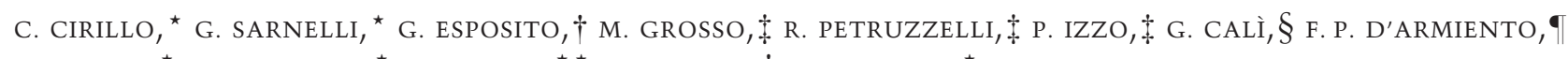
A. ROCCO,${ }^{\star}$ G. NARDONE, ${ }^{\star}$ T. IUVONE, ${ }^{\star}$ L. STEARDO $\dagger \&$ R. CUOMO ${ }^{\star}$

${ }^{\star}$ Department of Clinical and Experimental Medicine, Gastroenterological Unit, University Federico II, Naples, Italy

$\dagger$ Department of Human Physiology and Pharmacology 'V. Erspamer', Sapienza University, Rome, Italy

$\ddagger$ Department of Biochemistry and Medical Biotechnologies, University Federico II, Naples, Italy

§CNR-IEOS c/o Department of Cellular and Molecular Biology and Pathology 'L. Califano', University Federico II, Naples, Italy

-Department of Morphological and Functional Science, Pathology Unit, University Federico II, Naples, Italy

* Department of Experimental Pharmacology, University Federico II, Naples, Italy

\begin{abstract}
In the central nervous system glial-derived $S 100 B$ protein has been associated with inflammation via nitric oxide (NO) production. As the role of enteroglial cells in inflammatory bowel disease has been poorly investigated in humans, we evaluated the association of $S 100 B$ and NO production in ulcerative colitis (UC). S100B mRNA and protein expression, inducible NO synthase (iNOS) expression, and NO production were evaluated in rectal biopsies from 30 controls and 35 UC patients. To verify the correlation between $S 100 B$ and NO production, biopsies were exposed to $S 100 B$, in the presence or absence of specific receptor for advanced glycation end-products (RAGE) blocking antibody, to measure iNOS expression and nitrite production. S100B and iNOS expression were evaluated after incubation of biopsies with lipopolysaccharides (LPS) + interferon-gamma (IFN- $\gamma)$ in the presence of anti-RAGE or anti-S100B antibodies or budesonide. S100B mRNA and protein expression, iNOS expression and NO production were significantly higher in the rectal mucosa of patients compared to that of controls. Exogenous S100B induced a significant increase in both iNOS expression and NO production in controls and UC patients; this increase was inhibited by specific anti-RAGE blocking antibody. Incubation with LPS + IFN- $\gamma$ induced a signifi-
\end{abstract}

\section{Address for correspondence}

Professor Rosario Cuomo MD, Department of Clinical and

Experimental Medicine, Gastroenterological Unit, University

Federico II, Via S. Pansini 5, 80131 Naples, Italy.

Tel/fax: +39 0817463892 ;

e-mail: rcuomo@unina.it

Received: 28 January 2009

Accepted for publication: 26 April 2009 cant increase in $S 100 B \mathrm{mRNA}$ and protein expression, together with increased iNOS expression and NO production. LPS + IFN- $\gamma$-induced S100B up-regulation was not affected by budesonide, while iNOS expression and NO production were significantly inhibited by both specific anti-RAGE and anti-S100B blocking antibodies. Enteroglial-derived $S 100 B$ up-regulation in $U C$ participates in NO production, involving RAGE in a steroid insensitive pathway.

Keywords enteric glia, nitric oxide, S100B, ulcerative colitis.

\section{INTRODUCTION}

Enteric glial cells (EGC) represent an extensive cell population of the enteric nervous system within the gastrointestinal tract. Although they have so far been quite poorly described, evidence is accumulating that they are the morphological and functional equivalent of the astrocytes found in the central nervous system (CNS). ${ }^{1}$ In the brain, a factor released by astrocytes is S100B, a diffusible $\mathrm{Ca}^{+2} / \mathrm{Zn}^{+2}$-binding protein considered a 'janus face' neurotrophin. ${ }^{2,3}$ Indeed, once released, it has opposite effects depending upon its concentrations in the extracellular milieu: a pro-survival effect on neurons and neurites outgrowth at nanomolar concentrations, and a toxic effect at micromolar concentrations. ${ }^{3}$ S100B reaches micromolar concentrations during CNS neuro-inflammatory processes, thus stimulating the expression of inducible nitric oxide (NO) synthase (iNOS) protein and, consequently, inducing NO production acting as a full title brain cytokine. ${ }^{4-6}$ 
In the gut, EGC have been traditionally regarded as passive, supporting partners of enteric neurons. However, the recent studies have demonstrated the active role of enteric glia in maintaining and regulating gut homeostasis. ${ }^{7-9}$ The fundamental role played by EGC was demonstrated in a transgenic mouse model in which enteric glia were specifically ablated, resulting in fulminating intestinal inflammation. ${ }^{10}$ In vitro experiments showed that chronic activation of EGC causes the release of pro-inflammatory cytokines and NO in the enteric neuro-immune network. ${ }^{11,12}$ Alterations in enteroglial structure have been described in patients with inflammatory bowel diseases (IBD) ${ }^{13}$ but EGC activation and, more specifically, the role of enteroglial-derived S100B protein ${ }^{14,15}$ in the pathophysiology of gut inflammation, are still far from being fully characterized.

We recently demonstrated that $\mathrm{S} 100 \mathrm{~B}$ is up-regulated and stimulates NO production in the duodenal mucosa of patients with celiac disease. ${ }^{16}$ As increased NO production by iNOS has been involved in the pathogenesis of IBD, ${ }^{17-20}$ and, to clarify the role of enteric glia during chronic intestinal inflammation, the present study was undertaken to evaluate the expression of S100B in the rectal mucosa of patients with ulcerative colitis (UC), and its relationship with NO production.

In addition, to further investigate the primary role of enteric glia during the intestinal inflammatory scenario, we evaluated S100B expression in an in vitro model of intestinal inflammation by stimulating rectal mucosal biopsies with lipopolysaccharides (LPS) and interferon-gamma (IFN- $\gamma$ ).

\section{METHODS}

\section{Patients}

The experimental groups comprised 65 subjects: 35 patients with newly diagnosed UC (median age 35 years, range 25-47 years; 20 females/15 males) and 30 controls (median age 50 years, range $43-$ 65 years, 18 females $/ 12$ males). Controls were recruited from subjects undergoing colonoscopy for cancer screening; in all the morphology of the rectal mucosa was normal. All patients underwent endoscopic rectal biopsy for histological assessment. We obtained informed consent from all the participants. The study was approved by the Ethics Committee of the Federico II University of Naples.

\section{Tissue culture}

According to Coeffier et al., ${ }^{21}$ rectal biopsy specimens were placed in 24-well plates and cultured in Dulbecco Modified Eagle's medium supplemented with $5 \%$ fetal bovine serum, $2 \mathrm{mmol} \mathrm{L}^{-1}$ glutamine, $100 \mathrm{U} \mathrm{mL}^{-1}$ penicillin, $100 \mu \mathrm{g} \mathrm{mL}^{-1}$ streptomycin (Biowhittaker, Milan, Italy) at $37^{\circ} \mathrm{C}$ in $5 \% \mathrm{CO}_{2} / 95 \%$ air for
$24 \mathrm{~h}$. The release of S100B and nitrite levels, using Griess reagents, ${ }^{22}$ were measured in the supernatant in the different experimental conditions.

\section{Immunohistochemistry assay}

For S100B immunohistochemistry, rectal biopsy specimens were fixed in buffered formalin, embedded in paraffin and cut into $4 \mu \mathrm{m}$-thick serial sections. Sections were stained with the primary S100B antibody (1:200; NeoMarker, Fremont, CA, USA). After three 5-min washes, the secondary antibody was added and the samples were incubated at room temperature for $20 \mathrm{~min}$. The streptavidin-HRP detection system (Chemicon Int., Temecula, CA, USA) was added and samples were incubated at room temperature. After three 5-min washes, $50 \mu \mathrm{L}$ of chromogen was added and the reaction terminated after $1 \mathrm{~min}$ in water. Sections were then counterstained with haematoxylin eosin at room temperature. Negative controls were performed by omitting primary antibody.

\section{Double immunofluorescence staining for glial fibrillary acidic protein and S100B}

In order to demonstrate enteroglial origin of S100B protein, we performed double immunofluorescence for glial fibrillary acidic protein (GFAP)/S100B in rectal biopsy specimens. Tissues were fixed in buffered formalin, embedded in paraffin and cut into $4 \mu \mathrm{m}$-thick serial sections. Sections were deparaffinized and hydrated and subsequently blocked with $10 \%$ goat serum and $10 \%$ fetal calf serum in phosphate buffer saline (PBS) 1X (blocking buffer) for $2 \mathrm{~h}$ at room temperature. Tissue sections were then exposed to primary antibodies mouse anti-S100B (1:1000; AbCam, Cambridge, UK) and rabbit anti-GFAP (1 : 1000; AbCam), which were also diluted in the blocking buffer, $24 \mathrm{~h}$ at room temperature. After incubation, sections were rinsed in PBS 1X $(3 \times 10 \mathrm{~min})$, subsequently incubated at room temperature for $1 \mathrm{~h}$ with the secondary antibodies anti-mouse $(1: 200$; Alexa fluor 546; Invitrogen, Milan, Italy) and anti-rabbit (1:200; Alexa fluor 488; Invitrogen) and finally mounted in PBS/glycerol (1:1). Immunofluorescence analysis was performed at a confocal laser scanner microscope (LSM 510; Zeiss, Gottingen, Germany). The lambda of the argon ion laser was set at $488 \mathrm{~nm}$, and that of the $\mathrm{HeNe}$ laser was set at $543 \mathrm{~nm}$. Fluorescence emission was revealed by BP 505-530 band pass filter for Alexa Fluor 488 and by BP 560-615 band pass filter for Alexa Fluor 546.

\section{RNA isolation and quantitative real-time polymerase chain reaction}

Total RNA was isolated from homogenized tissue using Trizol reagent (Invitrogen), according to the manufacturer's instructions. One microgram of total RNA was used to generate a complementary DNA (cDNA) template using a reaction mix containing $4 \mu \mathrm{L}$ of $5 \times$ Reverse Transcriptase Buffer, $2 \mu \mathrm{L}$ of pDN6 $50 \mu \mathrm{mol} \mathrm{L}^{-1}, 2 \mu \mathrm{L}$ of $100 \mathrm{mmol} \mathrm{L}^{-1}$ dithiothreitol, $0.2 \mu \mathrm{L}$ of $100 \mathrm{mmol} \mathrm{L}^{-1} \mathrm{dNTP}$ mix, $4 \mu \mathrm{L}$ of $25 \mathrm{mmol} \mathrm{L}^{-1} \mathrm{MgCl}_{2}, 1 \mu \mathrm{L}$ of RNAsi 20 units $\mu \mathrm{L}^{-1}$ and 200 units of MMLV Reverse Transcriptase (Invitrogen). The total reaction volume was $20 \mu \mathrm{L}$. The mixture was incubated at $25^{\circ} \mathrm{C}$ for $10 \mathrm{~min}$ and subsequently at $42{ }^{\circ} \mathrm{C}$ for $45 \mathrm{~min}$. The reaction was stopped by heating at $99^{\circ} \mathrm{C}$ for $3 \mathrm{~min}$. Quantitative real-time polymerase chain reaction (PCR) for S100B and $\beta$-actin was performed on an iCycler instrument from Bio-Rad Laboratories (Hercules, CA, USA) using the Bio-Rad iCycler IQ ${ }^{\mathrm{TM}}$ Real-Time PCR 
Detection System Software (version 3.0A) for data acquisition and analysis. Amplification of $\mathrm{S} 100 \mathrm{~B}$ and $\beta$-actin fragments was performed using the SYBR Green PCR master mix (Bio-Rad Laboratories). ${ }^{23}$ Primer sequences used were S100B forward: GTGACTTCCAGGAATTCATGGC; S100B reverse: CAGGAAAGGTTTGGCTGCTT; $\beta$-actin forward: CGACAGGATGCAGAAGGAGA; $\beta$-actin reverse: CGTCATACTCCTGCTTGCTG. Reaction conditions were $3 \mathrm{~min}$ at $95^{\circ} \mathrm{C}$ followed by 40 cycles at $95{ }^{\circ} \mathrm{C}$ for $15 \mathrm{~s}, 55^{\circ} \mathrm{C}$ for $30 \mathrm{~s}, 72{ }^{\circ} \mathrm{C}$ for $20 \mathrm{~s}$. S100B mRNA was then normalized to the respective amount of $\operatorname{con}$ trol $\beta$-actin. To evaluate real-time PCR efficiencies, a 10-fold serially diluted cDNA was used for each amplicon and the slope values given by the instrument were used in the following formula: Efficiency $=[10(1 /$ slope $)]-1$. All primer sets had efficiencies of $100 \%(+/-10 \%)$. The comparative-threshold cycle (CT) method against the expression level of $\beta$-actin was used for quantization. The data are expressed as the increase compared to biopsy specimens cultured in medium alone after normalization to $\beta$-actin mRNA. Each experiment was performed in triplicate.

\section{Protein extraction and western immunoblot analysis}

Biopsy specimens were rapidly homogenized in $60 \mu \mathrm{L}$ of ice-cold hypotonic lysis buffer and incubated in ice for $45 \mathrm{~min}$. After this time, the cytoplasmatic fraction was then obtained by centrifugation at $13000 \mathrm{~g}$ for $15 \mathrm{~min}$ and protein concentration was determined with Bio-Rad assay kit. Equivalent amounts of each sample were denatured, separated on a $10 \%$ sodium dodecyl sulfate-polyacrylamide gel, and transferred to a nitrocellulose membrane (Amersham, Milan, Italy). Membranes were blocked for $2 \mathrm{~h}$ at room temperature in milk buffer ( $10 \%$ non-fat dry milk) and then incubated overnight at $4{ }^{\circ} \mathrm{C}$ with anti-S100B (1:1000; AbCam) or anti-iNOS (1:2000; Pharmingen, Milan, Italy) mouse monoclonal antibodies. Subsequently, the membranes were incubated for $2 \mathrm{~h}$ at room temperature with anti-mouse IgG conjugated to horseradish peroxidase (1:2000; AbCam). After washing, the membranes were analysed by enhanced chemiluminescence (ECL+; Amersham) and the optical density of the immunoreactive bands was determined by an image analysis system (GS-700 imaging densitometer, Bio-Rad Laboratories).

\section{Enzyme-linked immunosorbent assay for S100B}

Enzyme-linked immunosorbent assay (ELISA) for S100B was carried out on tissue supernatants as described by Green et al. ${ }^{24}$ Briefly, $50 \mu \mathrm{L}$ of sample plus $50 \mu \mathrm{L}$ of Tris buffer were applied on a microtitre plate previously coated with monoclonal anti-S100B (1: 1000; AbCam) in carbonate buffer and blocked with $1 \%$ bovine serum albumin. After washing, peroxidase-conjugated anti-S100 ( $1: 2000 ; \mathrm{AbCam})$ was added and incubation continued for $1 \mathrm{~h}$. The plate was washed, $0.2 \mathrm{~mL}$ of peroxidase substrate (Fast OPD; Sigma, Milan, Italy) were added and the plate incubated for a further 30-min period in the dark. Absorbance was measured at $450 \mathrm{~nm}$ on a microtitre plate reader. S100B levels in the culture medium were determined using a standard curve of S100B.

\section{Effects of exogenous S100B on iNOS protein expression}

In a second set of experiments, the effect of exogenous purified S100B protein on iNOS protein expression and relative NO production was assessed by incubating cultured biopsies with
S100B $5 \mu \mathrm{M}$ (AbCam) for $24 \mathrm{~h}$. This maximal concentration was based on a dose-response curve obtained by incubation of control biopsies to increasing concentrations of S100B $(0.005-5 \mu \mathrm{M})$ and according to our previous report. ${ }^{16}$

In parallel, paired biopsy specimens from controls and UC patients were incubated for $24 \mathrm{~h}$ with exogenous S100B alone, or in the presence of either budesonide ${ }^{25}\left(30 \mathrm{nmol} \mathrm{L}^{-1}\right.$; Sigma) or specific receptor for advanced glycation end-products (RAGE) blocking antibody ${ }^{26}$ (1: 10000-1:1000, dil. v/v; R\&D Systems, Minneapolis, MN, USA) to evaluate iNOS protein expression and NO production. Budesonide was added to culture medium $2 \mathrm{~h}$ before S100B exposure whereas specific RAGE blocking antibody was added $30 \mathrm{~min}$ before S100B stimulus.

\section{Effects of LPS plus IFN- $\gamma$ on S100B mRNA, protein expression and release, iNOS protein expression and nitrite production}

To evaluate the specific involvement of S100B increase in intestinal inflammation and its implications in NO production, further experiments were performed by incubation of cultured biopsies with a mixture of LPS and IFN- $\gamma$, which was previously demonstrated to stimulate NO production in human rectal mucosa. ${ }^{25}$ In brief, mucosal biopsy specimens were incubated for $24 \mathrm{~h}$ with LPS plus IFN- $\gamma\left(10 \mu \mathrm{g} \mathrm{mL}^{-1}\right.$ and $300 \mathrm{U} \mathrm{mL}^{-1}$, respectively, both from Sigma). S100B mRNA, protein expression and secretion were then evaluated in the presence and in the absence of budesonide ( $30 \mathrm{nmol} \mathrm{L}^{-1}$, Sigma), while iNOS protein expression and nitrite accumulation were measured in the presence of either S100B blocking antibody ${ }^{16}$ (1: 1000, dil. v/v, Abcam) or specific RAGE blocking antibody ${ }^{26}(1: 1000$, dil. v/v, $\mathrm{R} \& \mathrm{D}$ Systems). Control experiments were performed by incubating mucosal biopsies from UC patients in the presence of antiS100B or anti-RAGE neutralizing antibodies and in the absence of any stimulation. An isotype match IgG anti-GFAP antibody ${ }^{16}$ (1: $1000 \mathrm{v} / \mathrm{v}$ dil.; AbCam) served as control (data not shown). S100B mRNA, protein expression and iNOS protein expression were then measured in tissue, while the supernatant was analysed for S100B protein secretion and nitrite release. Effective budesonide concentration was in the range of the plasma levels typically achieved during treatment with steroids for active UC. ${ }^{27}$ Mucosal viability was assessed by $\mathrm{LDH}$ release in the medium at the beginning and after $24 \mathrm{~h}$ of incubation.

\section{Statistical analysis}

The normal distribution of the data was verified by the Komolgorov-Smirnov test for normality. Statistical analysis was thus performed with ANOVA, and multiple comparisons with Bonferroni's test. Results were expressed as the mean \pm SD of $n$ experiments. The level of statistical significance was fixed at $P<0.05$.

\section{RESULTS}

\section{Basal S100B mRNA, protein expression and release, iNOS protein expression and NO production}

In the Fig. 1 it is reported that $\mathrm{S} 100 \mathrm{~B}$ is a valid marker of rectal mucosal EGC as it mostly co-localizes with 

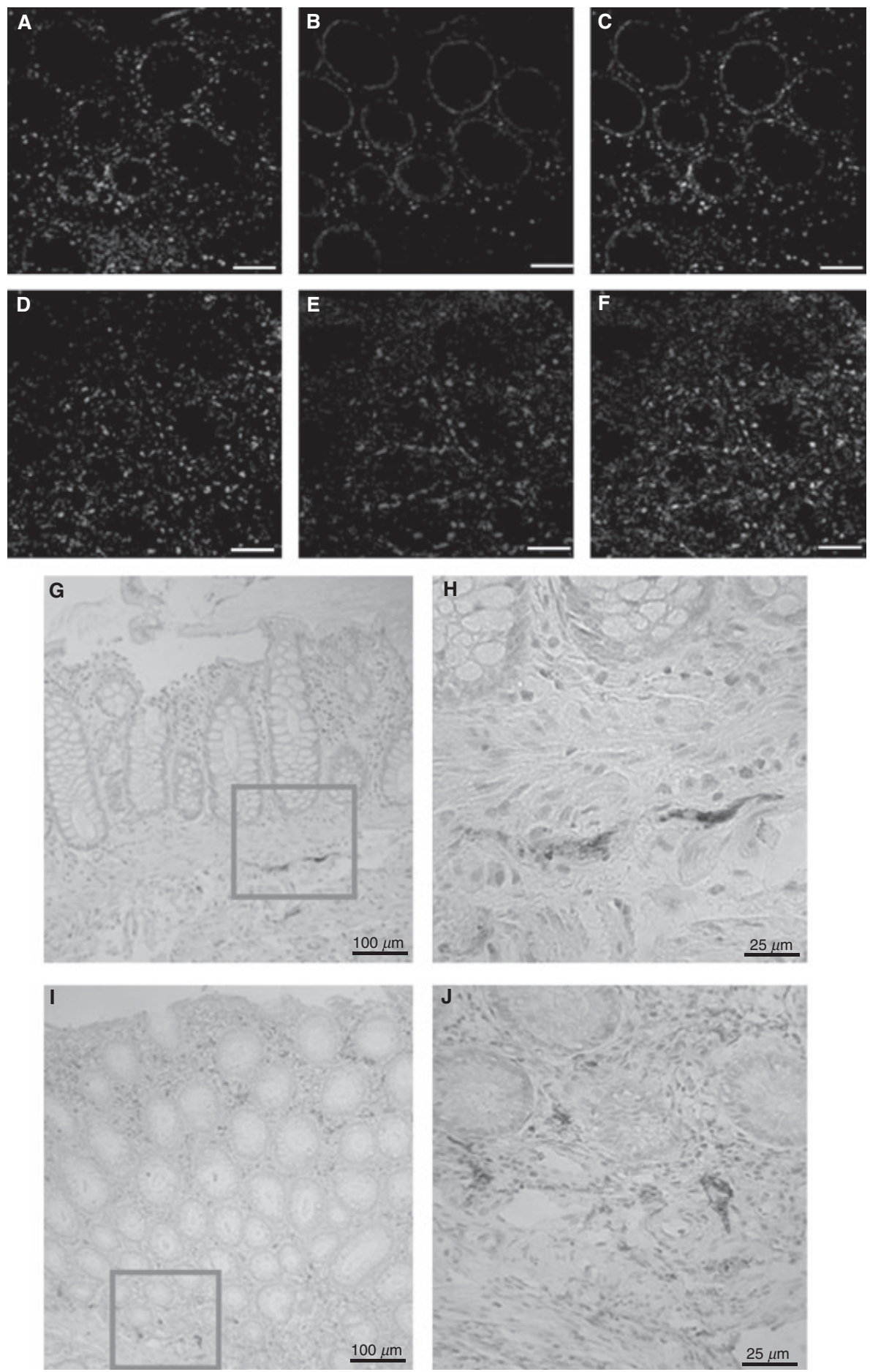

Figure 1 (Upper panel) GFAP/S100B co-localization in the rectal mucosa of controls (A-C) and UC patients (D-F). Representative pictures of rectal mucosal biopsies double labelled with anti-GFAP and anti-S100B antibodies (A, D and B, E respectively). Panels (C and F) illustrate merged images in which it appears that S100B immunoreactivity mostly co-localizes with the GFAP positive enteroglial mucosal network. Note the slight immunoreactivity increase for both GFAP and S100B in UC compared to controls (A-C and D-F respectively). Scale bar $=50 \mu \mathrm{m}$. (Lower panel) S100B immunoreactivity in the rectal mucosa of controls ( $\mathrm{G}$ and H) and UC patients (I and J). UC patients displayed stronger S100B immunopositivity in the submucosa, along with S100B immunoreactivity in the mucosa (scale bar $=100 \mu \mathrm{m}$ ). Note that S100B immunopositivity was not present in immune cells ( $\mathrm{H}$ and $\mathrm{J})$. In controls and UC patients ( $\mathrm{H}$ and $\mathrm{J}$, respectively), the pattern of S100B-positive enteric glia is represented at high magnification (scale bar $=25 \mu \mathrm{m}$ ). 
GFAP in both controls and UC patients (panels Fig. 1A-C and Fig. 1D-F respectively). Further immunohistochemistry demonstrated that S100B immunopositivity was most readily detectable and confined within the submucosa, with only few EGC processes extended to the mucosa (Fig. 1G and H). In contrast, in UC patients, a stronger and diffuse S100B immunoreactivity was present in the submucosa, together with a marked S100B positivity in the mucosa (Fig. 1I and J).

Accordingly, we observed that both mucosal S100B mRNA $(\sim 38$-fold, $P<0.01)$ and protein expression $(1476 \pm 18 \%, P<0.01)$ were significantly higher in UC patients than in controls (Fig. $2 \mathrm{~A}$ and B). In the Fig. $2(\mathrm{C})$, we show that rectal biopsy specimens of patients with colitis were also able to secrete higher levels of S100B in the culture medium than those of control subjects $(538 \pm 50 \%, P<0.01)$.

As expected, in basal conditions, mucosal iNOS protein expression and NO production in the culture medium were significantly higher $(1031 \pm 33 \%$ and
$268 \pm 38 \%, P<0.01$, respectively) in the rectal biopsies of UC patients than in those of controls (Fig. 2D and E).

\section{S100B-induced iNOS protein expression and NO production}

In in vitro experiments, we found that a $24-\mathrm{h}$ incubation of controls' biopsy specimens with exogenous S100B significantly increased in a concentrationdependent fashion both tissue iNOS protein expression and NO levels in the culture medium compared to unstimulated biopsy specimens (Fig. 3A and B). As showed in the Fig. 4(A and B), S100B-dependent increased NO production was significantly inhibited by specific RAGE blocking antibody in a concentration-dependent fashion, and by budesonide.

In rectal biopsies from UC patients, the increase in S100B-mediated iNOS protein expression and NO production were also significantly inhibited by RAGE blocking antibody and by budesonide (Fig. 4C and D).

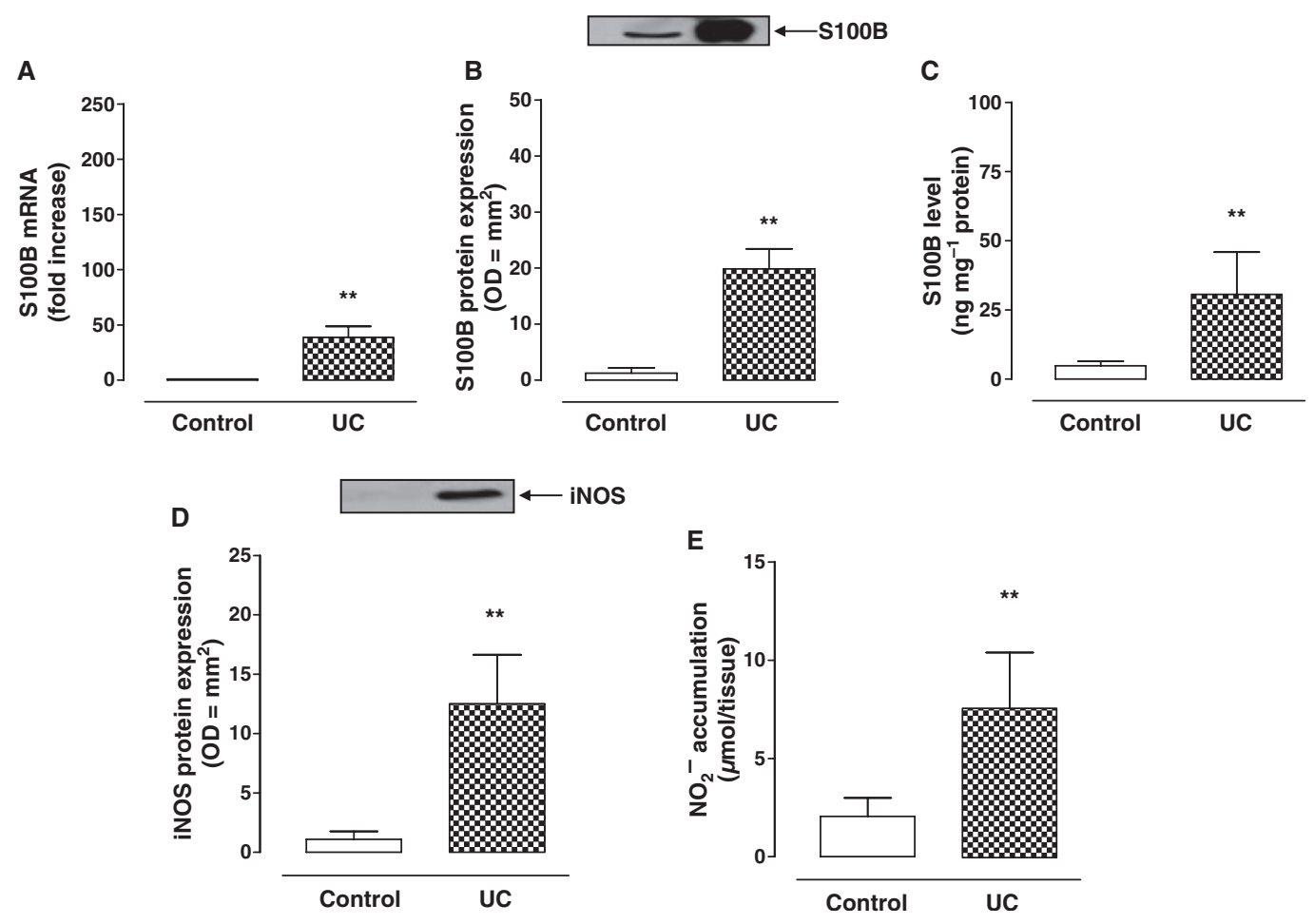

Figure 2 (A) S100B mRNA expression by quantitative real-time PCR. S100B mRNA was higher in patients with UC than in control subjects. The extent of the increase was compared to that of the control group, after normalization to $\beta$-actin mRNA. Each bar is the mean \pm SD of eight experiments, ${ }^{\star \star} P<0.01$. (B) Western blot analysis showing the expression of S100B protein in controls and patients with colitis. Upper panel: S100B protein expression in tissue homogenates; graph: densitometric analysis of the corresponding bands. The upper panel refers to $n=30$ experiments. Each bar in the graph is the mean \pm SD of 30 experiments. ${ }^{\star \star} P<0.01$ vs controls. (C) Increase in S100B release by rectal biopsy specimens from UC patients vs control subjects. Each bar is the mean \pm SD of 30 experiments. ${ }^{\star \star} P<0.01$ vs controls. (D) Western blot analysis showing the expression of iNOS protein in controls and patients with colitis. Upper panel: iNOS protein expression in tissue homogenates; graph: densitometric analysis of the corresponding bands. The upper panel refers to $n=30$ experiments; each bar in the graph is the mean $\pm \mathrm{SD}$ of 30 experiments. ${ }^{\star \star} P<0.01$ vs controls. (E) NO medium accumulation in control subjects and UC patients cultured biopsies. NO production was assessed measuring the accumulation of nitrite in culture medium at $24 \mathrm{~h}$. Each bar is the mean $\pm \mathrm{SD}$ of 30 experiments. ${ }^{\star \star} P<0.01 \mathrm{vs}$ controls. 

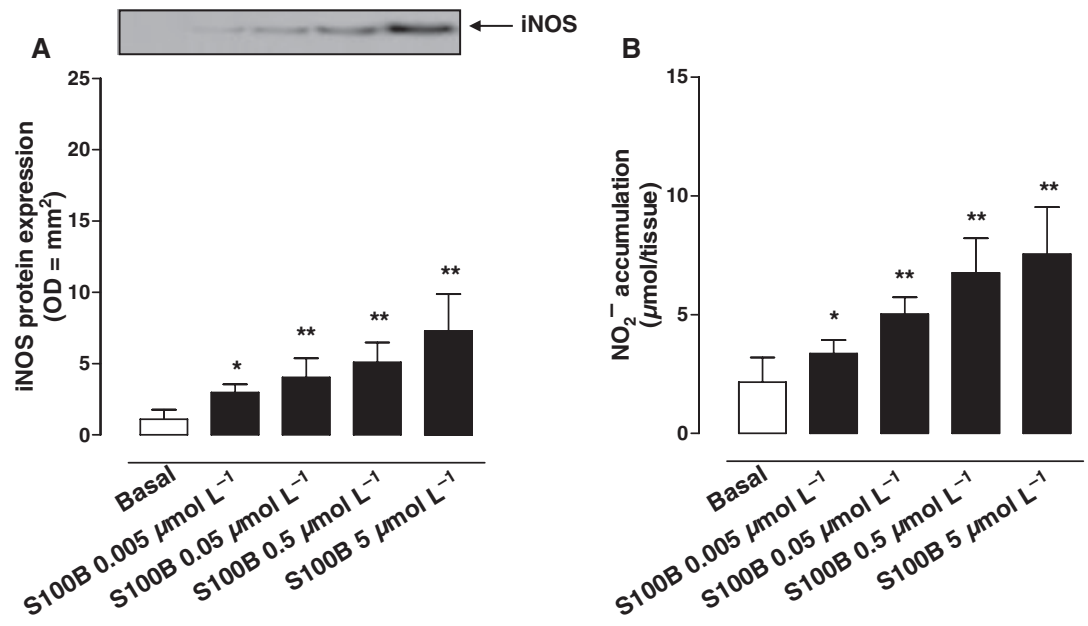

Figure 3 (A) Western blot analysis showing the effect of S100B $(0.005-5 \mu \mathrm{M})$ on iNOS protein expression at $24 \mathrm{~h}$. Upper panel: iNOS protein expression in tissue homogenates; graph: densitometric analysis of the corresponding bands. The upper panel refers to $n=15$ separate experiments; each bar in the graph is the mean \pm SD of 15 experiments. ${ }^{\star} P<0.05,{ }^{\star}{ }^{\star} P<0.01$ vs unstimulated. (B) Effect of S100B $(0.005$ $5 \mu \mathrm{M}$ ) on nitrite production in cultured controls biopsies. Nitrite production was determined by measuring the accumulation of nitrite in culture medium. Each bar is the mean \pm SD of 15 experiments. ${ }^{*} P<0.05$, ${ }^{\star \star} P<0.01$ vs unstimulated.

A positive correlation between $\mathrm{S100B}$ and nitrite production was observed in both basal and stimulated conditions, but it did not reach statistical significance (data not shown).

\section{Effect of LPS + IFN- $\gamma$ on S100B mRNA, protein expression and release}

When biopsy specimens from controls and UC patients were exposed for $24 \mathrm{~h}$ to LPS plus IFN- $\gamma$, we observed a significant increase in S100B mRNA ( $\sim 20$-fold and $\sim$ fourfold, $P<0.01$ respectively), protein expression $(191 \pm 50 \%$ and $97 \pm 16 \% P<0.01$, respectively) and secretion $(296 \pm 63 \%$ and $150 \pm 29 \%$, $P<0.01$, respectively), which, most interestingly, were not affected by preincubation with budesonide (Fig. 5A-F).

\section{Effect of LPS + IFN- $\gamma$ on iNOS protein expression and NO production}

Besides S100B up-regulation, incubation of biopsy specimens from controls and UC patients with LPS plus IFN- $\gamma$ resulted in a significant increase of both iNOS protein expression and NO production, which were significantly inhibited by preincubation with budesonide (Fig. 6A-D).

In the same experimental conditions, preincubation with specific RAGE blocking antibody $30 \mathrm{~min}$ before LPS + IFN $-\gamma$ addition, significantly inhibited both iNOS protein expression and NO production (Fig. 6A-D). Similarly, anti-S100B antibody added $30 \mathrm{~min}$ before LPS + IFN $-\gamma$ challenge, caused a significant inhibition of iNOS protein expression and NO production in both controls and UC patients (Fig. 6A-D). Further supporting the specificity of S100B-mediated responses,
LPS + IFN- $\gamma$-induced nitrite production in biopsy specimens was unaffected by preincubation with anti-GFAP antibody (data not shown). In our hands, both anti-S100B and anti-RAGE antibodies, in the absence of any stimulation, were not able to reduce iNOS expression and nitrite production in UC biopsies (data not shown).

\section{DISCUSSION}

Several studies suggest the involvement of enteric glia in $\mathrm{IBD},{ }^{13,28}$ although clear evidence that EGC are directly involved in the mechanism of gut inflammation in humans is still lacking. Changes in enteroglial architecture, with proliferation of EGC, have indeed been previously reported in patients with $\mathrm{IBD}_{1}{ }^{28,29}$ but, here again, the significance of this phenomenon is still not totally clear.

Here, we provide evidence that EGC directly participate to chronic mucosal inflammation of patients with UC. The enteroglial-derived S100B protein is physiologically expressed by, and represents a specific marker for the identification and activation of enteroglial cells. ${ }^{15,16}$ Here, we confirm that S100B is a good marker for EGC, since it mostly co-localizes with GFAP in the enteroglial network of mucosal biopsies from human rectum. However, as evident in the Fig. $1(\mathrm{C})$, some GFAP positive EGC do not express S100B. As recently reported in human isolated ganglia, this finding is probably related to some limitations of the immunofluorescence technique, like an irregular S100B antibody penetration. ${ }^{30}$

In the present study we showed that in the rectal mucosa of UC patients there is an increased S100B immunoreactivity, together with a significant increase in S100B mRNA, protein expression and secretion. 

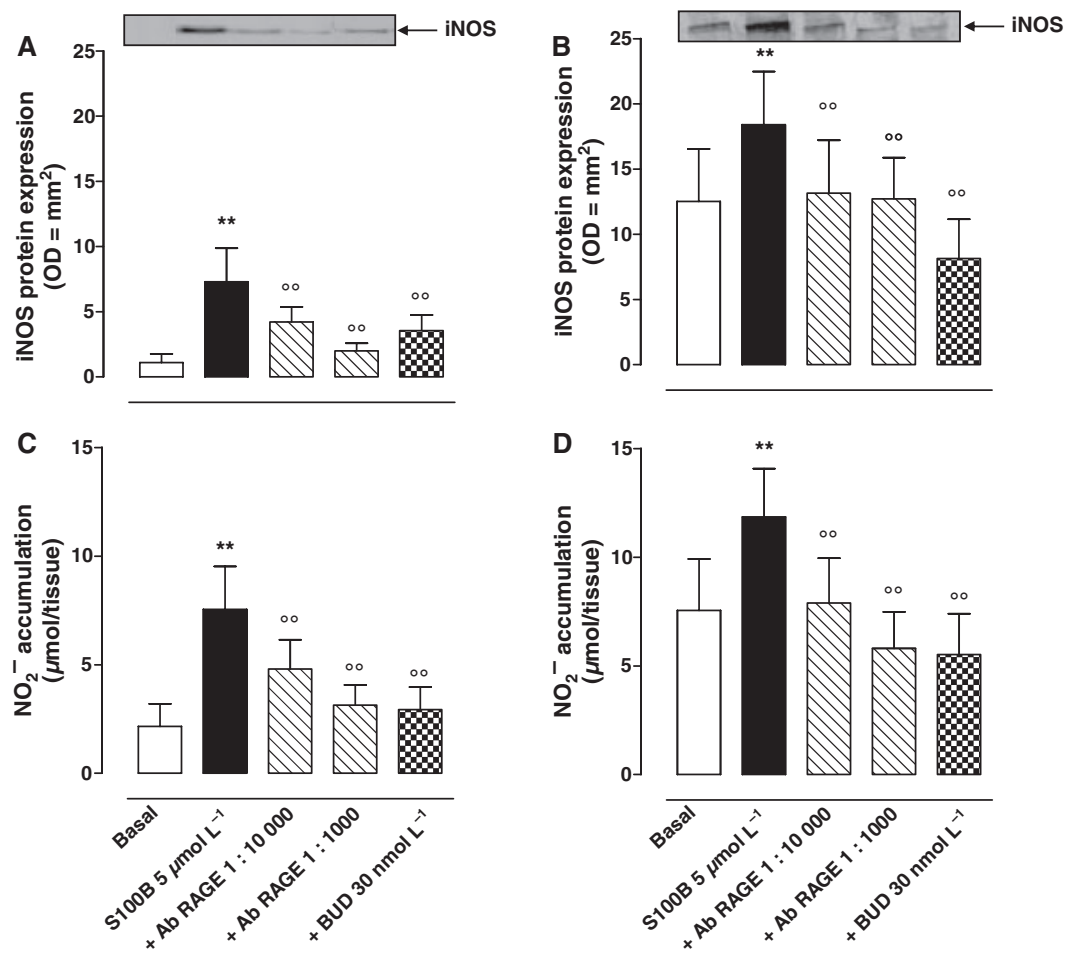

Figure 4 Western blot analysis showing the effect of exogenous S100B $(5 \mu \mathrm{M})$, in the presence or absence of budesonide (30 nM) or anti-RAGE antibody (1:10 000-1:1000, dil. v/v), on iNOS protein expression at $24 \mathrm{~h}$ in cultured biopsies from controls (A) and UC patients (B). Upper panel: iNOS protein expression in tissue homogenates; graph: densitometric analysis of the corresponding bands. The upper panel refers to $n=15$ experiments; each bar in the graph is the mean $\pm \mathrm{SD}$ of 15 experiments. ${ }^{\star \star} P<0.01$ vs unstimulated; ${ }^{\circ} P<0.01$ vs untreated. Effect of exogenous S100B $(5 \mu \mathrm{M})$, in the presence or absence of budesonide $(30 \mathrm{nM})$ or anti-RAGE antibody $(1: 1000, \mathrm{dil} . \mathrm{v} / \mathrm{v})$, on NO production at $24 \mathrm{~h}$ in cultured biopsies from controls $(C)$ and UC patients (D). NO production was determined by measuring the accumulation of nitrite in culture medium. Each bar is the mean $\pm \mathrm{SD}$ of 15 experiments. ${ }^{\star}{ }^{\star} P<0.01$ vs unstimulated; ${ }^{\circ} P<0.01$ vs untreated.

This up-regulation is associated with enhanced NO production through the specific stimulation of iNOS.

A growing body of evidence indicates that UC is characterized by abnormal mucosal NO production consequent to iNOS induction by pro-inflammatory cytokines. ${ }^{25,31}$

In the brain, S100B has been demonstrated to promote the synthesis of NO through the induction of specific pro-inflammatory transcription factors, ${ }^{32-34}$ but the role of this protein in gut inflammation has been less investigated. Within this context, the ability of enteric glia to modulate NO production, and the specificity of S100B protein-mediated responses seems pivotal. In a previous study, we were able to demonstrate that the extent of S100B expression was associated with increased NO production in the duodenal mucosa of celiac patients. ${ }^{16}$ In the present study, we confirmed that the application of exogenous S100B induces a significant and concentration-dependent increase in NO production, through iNOS expression, also in the human rectal mucosa. While micromolar concentrations of S100B mediate a significant NO increase in UC patients, most interestingly, we observed that similar concentrations of this protein were also able to stimulate NO production in the rectal mucosa of controls. This finding suggests that enteric glia is able to mediate mucosal NO-dependent inflammatory responses by increasing S100B protein concentrations.

Data from CNS indicate that S100B acts as extracellular ligand for cell surface receptors, such as RAGE, by triggering pro-inflammatory signals that lead to NO production. ${ }^{35,36}$ To the best of our knowledge, there are not previous reports discussing whether a similar mechanism is involved in mediating S100B-responses in the gut. In our experimental setting, S100B-mediated NO production was significantly inhibited by preincubation with specific RAGE blocking antibody. It has been previously demonstrated that other members of this family (i.e. S100A12), play a role during intestinal inflammation in IBD via RAGE interaction. ${ }^{37}$ More specifically, the S100A12/RAGE-mediated pathway may affect immune cell-derived NO production. Although we cannot definitely rule out the effect of other inflammatory effectors in mediating iNOS induction in the mucosa of UC patients, our 
A
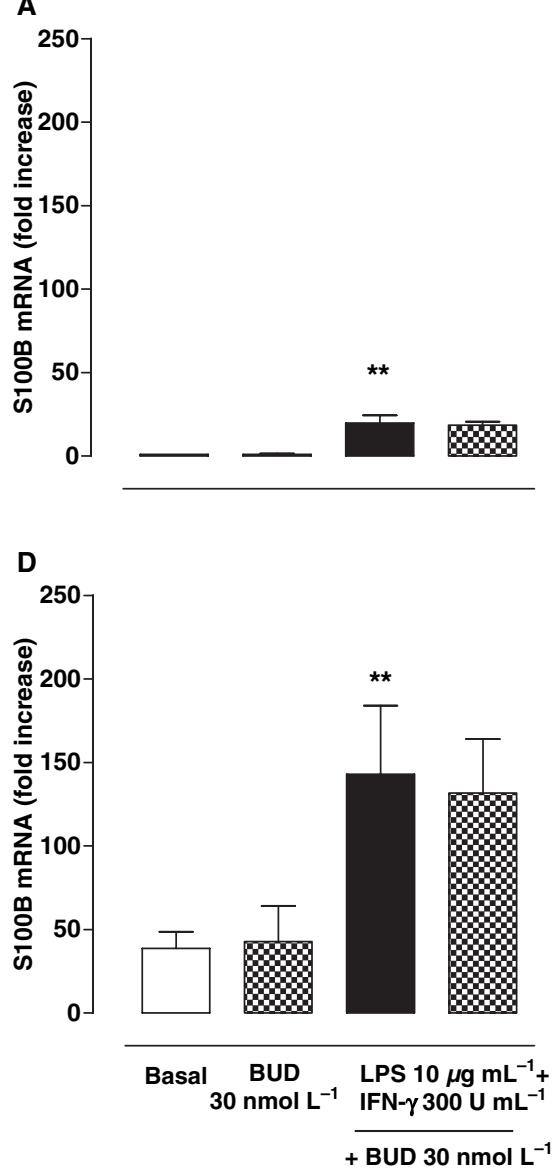

B

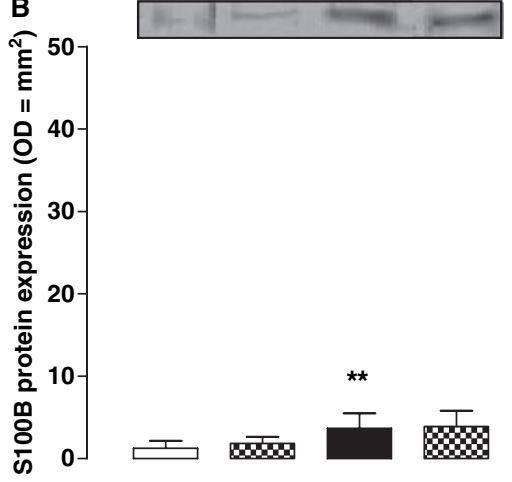

S
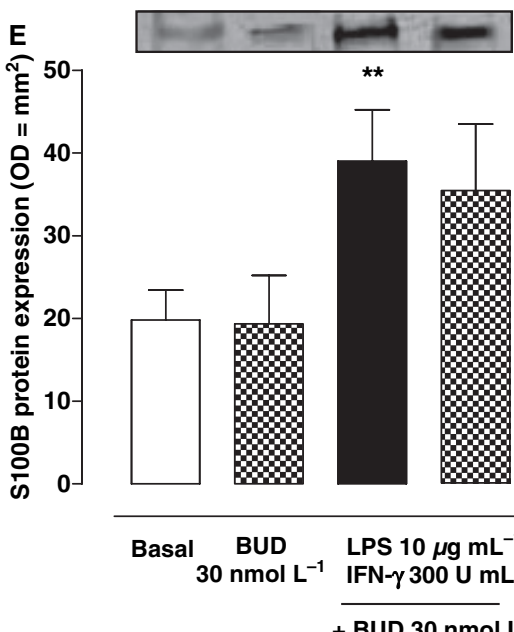

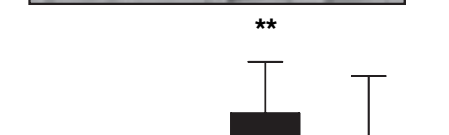

F

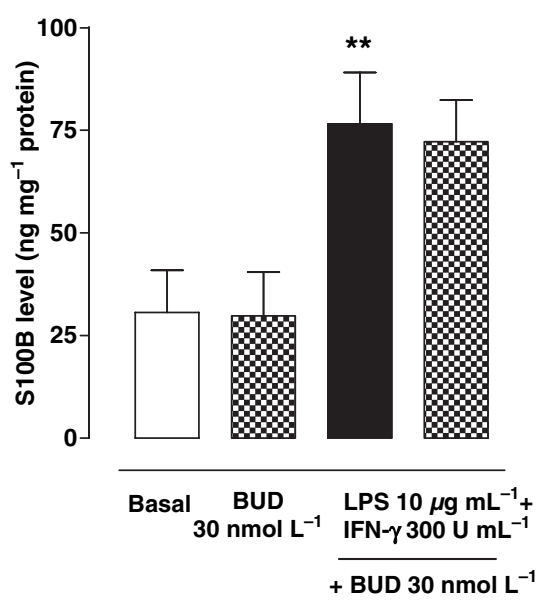

Figure 5 S100B mRNA expression by quantitative real-time PCR. S100B mRNA was increased at $24 \mathrm{~h}$ in controls (A) and UC patients (D) after the addition of LPS $\left(10 \mu \mathrm{g} \mathrm{mL}^{-1}\right)$ plus IFN- $\gamma\left(300 \mathrm{U} \mathrm{mL}^{-1}\right)$. S100B mRNA levels were quantified in relation to $\beta$-actin levels. No significant differences in the expression of the housekeeping gene ( $\beta$-actin) were found between treatment groups. Each bar shows the mean \pm SD of eight experiments. ${ }^{\star}{ }^{*} P<0.01$ vs unstimulated biopsies. Western blot analysis showing the effect of combination of LPS $\left(10 \mu \mathrm{g} \mathrm{mL}^{-1}\right) \mathrm{plus}$ IFN- $\gamma\left(300 \mathrm{U} \mathrm{mL}^{-1}\right)$, in the presence or absence of budesonide $(30 \mathrm{nM})$, on S100B protein expression at $24 \mathrm{~h}$ in cultured biopsies derived from control subjects (B) and UC patients (E). Upper panel: S100B protein expression in tissue homogenates; graph: densitometric analysis of the corresponding bands. The upper panel refers to $n=10$ experiments; each bar in the graph is the mean \pm SD of 10 experiments. ${ }^{\star}{ }^{\star} P<0.01$ vs unstimulated. Increased S100B release at $24 \mathrm{~h}$ by biopsies from control subjects (C) and UC patients (F) stimulated with LPS $\left(10 \mu \mathrm{g} \mathrm{mL}^{-1}\right)$ plus IFN- $\gamma\left(300 \mathrm{U} \mathrm{mL}^{-1}\right)$ in the presence or absence of budesonide $(30 \mathrm{nM})$. Each bar is the mean $\pm \mathrm{SD}$ of 10 experiments. ${ }^{\star *} P<0.01 \mathrm{vs}$ unstimulated.

results seem to suggest that enteroglial-derived S100B protein is likely to participate in NO production via a RAGE-dependent mechanism.

It has been hypothesized that EGC are part of the complex system of immunoregulatory effectors in the gut $^{3}{ }^{3}$ and, in vitro studies showed that treatment of EGC lines with a combination of pro-inflammatory cytokines induces the expression of major histocompatibility complex (MHC) class II molecules. ${ }^{29,38}$ Similarly, it has been reported that, in patients with IBD, enteroglial cells express MHC II. $^{29,39}$ These data may provide the initial evidence that EGC activation is involved in the intestinal inflammation that modulates immune responses.
To further confirm the specificity of inflammatoryinduced enteroglial activation, we tested S100B production in an experimental model of gut inflammation. In our experiments, the addition of LPS + IFN $-\gamma$ to rectal mucosa tissue, led to a significant increase in S100B mRNA, protein expression and release, together with an enhanced NO production. These findings indicate that EGC are able to recognize inflammatory stimuli and that, once activated, they produce and release S100B up to micromolar concentrations, thus contributing to the induction of iNOS. In addition, a positive but not significant correlation between S100B and nitrite production was observed in both basal and stimulated conditions, probably because NO 

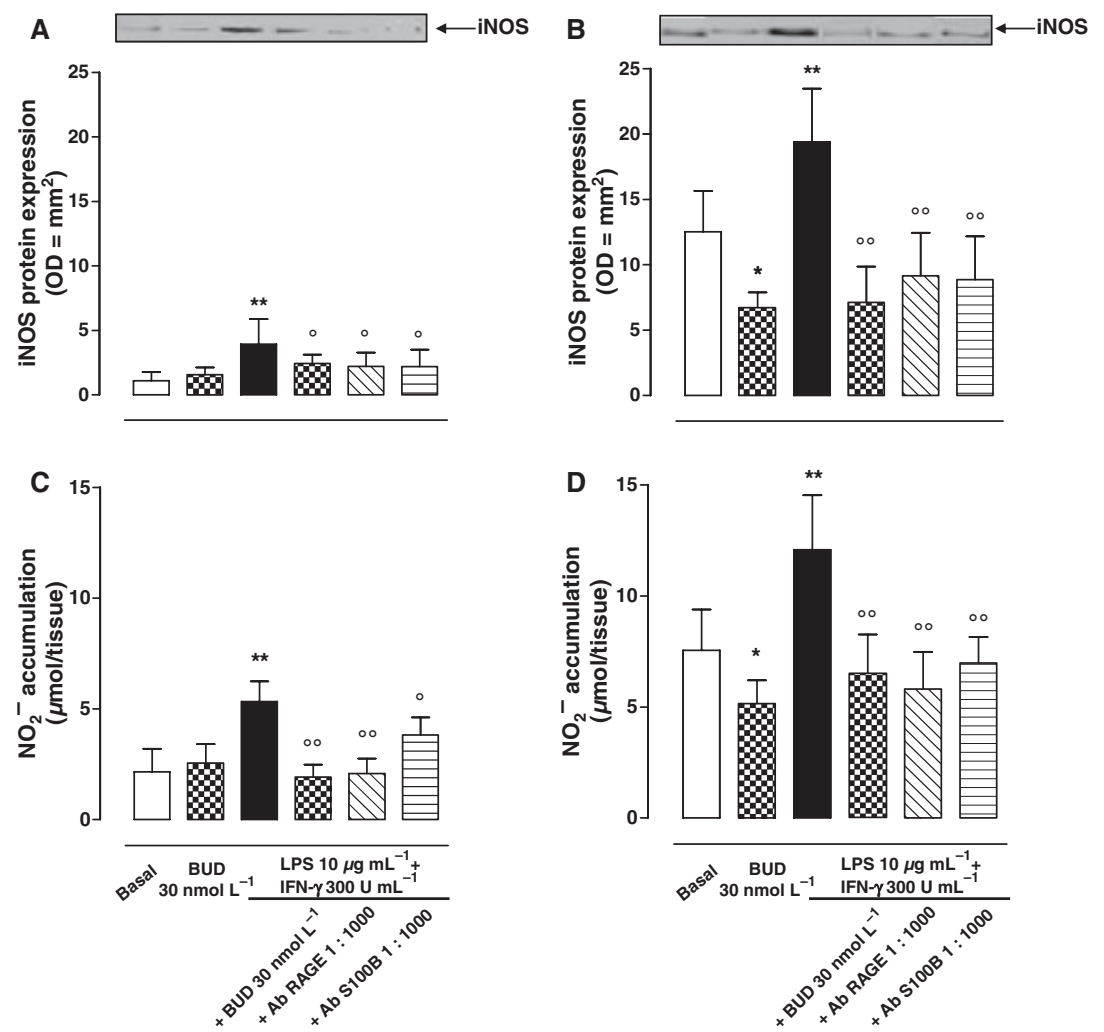

Figure 6 Western blot analysis showing the effect of LPS $\left(10 \mu \mathrm{g} \mathrm{mL}^{-1}\right)$ plus IFN- $\gamma\left(300 \mathrm{U} \mathrm{mL}^{-1}\right)$, in the presence or absence of budesonide $(30 \mathrm{nM})$, or anti-RAGE $(1: 1000$, dil. $\mathrm{v} / \mathrm{v})$ or anti-S100B $(1: 1000$, dil. $\mathrm{v} / \mathrm{v})$ blocking antibodies, on iNOS protein expression at $24 \mathrm{~h}$ in cultured biopsies derived from control subjects (A) and UC patients (B). Upper panel: iNOS protein expression in tissue homogenates; graph: densitometric analysis of the corresponding bands. The upper panel refers to $n=10$ experiments; each bar in the graph is the mean $\pm \mathrm{SD}$ of 10 experiments. ${ }^{\star} P<0.05$, ${ }^{\star \star} P<0.01 \mathrm{vs}$ unstimulated; ${ }^{\circ} \mathrm{P}<0.05,{ }^{\circ} \mathrm{P}<0.01$ vs untreated. Effect of LPS $(10 \mu \mathrm{g} \mathrm{mL}-1)$ plus IFN- $\gamma\left(300 \mathrm{U} \mathrm{mL}^{-1}\right)$, in the presence or absence of budesonide $(30 \mathrm{nM})$, or anti-RAGE $(1: 1000$, dil. v/v) or anti-S100B $(1: 1000$, dil. v/v) blocking antibodies, on NO production at $24 \mathrm{~h}$ in cultured biopsies derived from control subjects $(\mathrm{C})$ and UC patients $(\mathrm{D})$. NO production was determined measuring the accumulation of nitrite in culture medium. Each bar shows the mean $\pm \mathrm{SD}$ of 10 experiments. ${ }^{\star} P<0.05,{ }^{\star \star} P<0.01$ vs unstimulated; ${ }^{\circ} P<0.05,{ }^{\circ} P<0.01$ vs untreated.

production is also stimulated by other factors and is produced by different cell types.

In basal conditions, both anti-S100B and anti-RAGE antibodies were not able to reduce iNOS expression and nitrite production in UC biopsies. This finding is probably due to the fact that while such pathways are able to prevent the induction of iNOS, they are not affecting the enzymes that are already induced. Conversely, LPS + IFN- $\gamma$-induced NO production was significantly inhibited by preincubation with either antiS100B or anti-RAGE blocking antibodies, further confirming the specificity and the ability of enteroglialderived S100B protein to modulate intestinal inflammation, at least in part, by enhancing NO production.

In the study by Linehan et al., ${ }^{25}$ LPS + IFN- $\gamma$ had an excitatory effect, and budesonide an inhibitory effect on iNOS and NO production in colonic biopsies. As expected, in our experimental setting, budesonide significantly inhibited enhanced NO production, but, most importantly, it did not affect LPS + IFN- $\gamma$-induced S100B mRNA, protein expression and secretion, suggesting that enteroglial activation occurs via a steroid-insensitive mechanism.

In conclusion, we have demonstrated that EGC, via S100B up-regulation, actively participate to the increased NO production occurring in the mucosa of patients with UC.

Although other investigations are needed, our findings contribute to understand the role of enteric glia in the complex scenario of intestinal inflammation and pave the way to future therapeutic options targeting NO overproduction in IBD by acting on enteroglial activation.

\section{ACKNOWLEDGMENT}

The authors thank Rosanna Scala for her help with the preparation of the manuscript. 


\section{FUNDING}

This work was supported by research funds from the Italian Ministry of University and Research (COFIN Projects No. 2004062155 to GS and RC).

\section{CONFLICT OF INTEREST}

The authors have no competing interests.

\section{REFERENCES}

1 Sariola H, Saarma M. Novel functions and signalling pathways for GDNF. J Cell Sci 2003; 116: 3855-62.

2 Fanò $\mathrm{G}$, Biocca $\mathrm{S}$, Fulle $\mathrm{S}$ et al. The S100: a protein family in search of a function. Prog Neurobiol 1995; 46: 71-82.

3 Van Eldik LJ, Wainwright MS. The Janus face of glial-derived S100 beta: beneficial and detrimental function in the brain. Restor Neurol Neurosci 2003; 21: 97-108.

4 Griffin WS, Sheng JG, Royston MC et al. Glial-neuronal interactions in Alzheimer's disease: the potential role of a 'cytokine cycle' in disease progression. Brain Pathol 1998; 8: 65-72.

5 Petrova TV, Hu J, Van Eldik LJ. Modulation of glial activation by astrocyte-derived protein S100 beta: differential responses of astrocyte and microglial cultures. Brain Res 2000; 853: 74-80.

6 Adami C, Sorci G, Blasi E et al. S100 beta expression in and effects on microglia. Glia 2001; 33: 131-42.

7 Giaroni C, De Ponti F, Casentino M et al. Plasticity in the enteric nervous system. Gastroenterology 1999; 117: 1438-58.

8 Von Boyen GB, Reinshagen $M$, Steinkamp $M$ et al. Enteric nervous plasticity and development dependence on neurotrophic factors. J Gastroenterol 2002; 37: 583-8.

9 Ruhl A, Nasser Y, Sharkey KA. Enteric glia. Neurogastroenterol Motil 2004; 16: 44-9.

10 Bush TG, Savidge TC, Freeman TC et al. Fulminant jejuno-ileitis following ablation of enteric glia in adult transgenic mice. Cell 1998; 93: 189 201.

11 Collins SM. The immunomodulation of enteric neuromuscular function: implication for motility and inflammatory disorders. Gastroenetrology 1996; 111: 1683-99.

12 Ruhl A, Franzke S, Collins SM et al. Interleukin-6 expression and regulation in rat enteric glial cells. Am I Physiol Gastrointest Liver Physiol 2001; 280: 1163-71.
13 Cornet A, Savidge TC, Cabarrocas J et al. Enterocolitis induced by autoimmune targeting of enteric glial cells: a possible mechanism in Crohn's disease? Proc Natl Acad Sci 2001; 98: 13306-11.

14 Ferri GL, Probert L, Cocchia D et al. Evidence for the presence of S-100 protein in the glial component of the human enteric nervous system. Nature 1982; 297: 409-12.

15 Neunlist M, Aubert P, Bonnaud S et al. Enteric glia inhibit intestinal epithelial cell proliferation partly through a TGF-beta1-dependent pathway. Am I Physiol Gastrointest Liver Physiol 2007; 292: 231-41.

16 Esposito G, Cirillo C, Sarnelli G et al. Enteric glial-derived S100B protein stimulates nitric oxide production in celiac disease. Gastroenterology 2007; 133: 918-25.

17 Buhner S, Buning C, Genschel J et al. Genetic basis for increased intestinal permeability in families with Crohn's disease: role of CARD15 3020insC mutation? Gut 2006; 55: 342-7.

18 Kolios G, Petoumenos C, Nackos A. Mediators of inflammation: production and implication in inflammatory bowel disease. Hepatogastroenterology 1998; 45: 1601-9.

19 Kubes P, McCafferty DM. Nitric oxide and intestinal inflammation. Am J Med 2000; 109: 150-8.

20 Podolsky DK. Inflammatory bowel disease. N Engl J Med 2002; 347: 417 29.

21 Coeffier M, Miralles-Barrachina O, Le Pessot $\mathrm{F}$ et al. Influence of glutamine on cytokine production by human gut in vitro. Cytokine 2001; 13: 148 54.

22 Di Rosa M, Radomski M, Carnuccio $\mathrm{R}$ et al. Glucocorticoids inhibit the induction of nitric oxide synthase in macrophages. Biochem Biophys Res Commun 1990; 172: 1246-52.

23 Casabianca A, Orlandi C, Fraternale A et al. Development of a real-time PCR assay using SYBR Green I for provirus load quantification in a murine model of AIDS. I Clin Microbiol 2004; 42: 4361-4.
24 Green AJ, Keir G, Thompson EJ. A specific and sensitive ELISA for measuring S-100b in cerebrospinal fluid. I Immunol Methods 1997; 205: 35-41.

25 Linehan JD, Kolios G, Valatas V et al. Effect of corticosteroids on nitric oxide production in inflammatory bowel disease: are leukocytes the site of action? Am I Physiol Gastrointest Liver Physiol 2005; 288: G261-7.

26 Esposito G, Imitola J, Lu J et al. Genomic and functional profiling of human Down syndrome neural progenitors implicates S100B and aquaporin 4 in cell injury. Hum Mol Genet 2008; 17: 440-57.

27 Lundin PD, Edsbacker S, Bergstrand $M$ et al. Pharmacokinetics of budesonide controlled ileal release capsules in children and adults with active Crohn's disease. Aliment Pharmacol Ther 2003; 17: 85-92.

28 Geboes K, Collins S. Structural abnormalities of the nervous system in Crohn's disease and ulcerative colitis. Neurogastroenterol Motil 1998; 10: 189-202.

29 Cabarrocas I, Savidge TC, Liblau RS. Role of enteric glial cells in inflammatory bowel disease. Glia 2003; 41: 81-93.

30 Hoff S, Zeller F, von Weyhern CW et al. Quantitative assessment of glial cells in the human and guinea pig enteric nervous system with an antiSox8/9/10 antibody. I Comp Neurol 2008; 509: 356-71.

31 Menchen L, Colon AL, Madrigal JL et al. Activity of inducible and neuronal nitric oxide synthases in colonic mucosa predicts progression of ulcerative colitis. Am I Gastroenterol 2004; 99: 1756-64.

32 Goncalves DS, Lenz G, Karl J et al. Extracellular S100B protein modulates ERK in astrocyte cultures. NeuroReport 2000; 11: 807-9.

33 Lam AG, Koppal T, Akama KT et al. Mechanism of glial activation by S100B: involvement of the transcription factor NFkappaB. Neurobiol Aging 2001; 22: 765-72. 
$34 \mathrm{Hu}$ J, Ferreira A, Van Eldik LJ. S100 $\beta$ induces neuronal cell death through nitric oxide release from astrocytes. J Neurochem 1997; 69: 2294-301.

35 Hofmann MA, Drury S, Fu C et al. RAGE mediates a novel proinflammatory axis: a central cell surface receptor for S100/calgranulin polypeptides. Cell 1999; 97: 889901.

36 Schmidt AM, Yan SD, Yan SF et al. The multiligand receptor RAGE as a progression factor amplifying immune and inflammatory responses. I Clin Invest 2001; 108: 949-55.
37 Foell D, Kucharzik T, Kraft M et al. Neutrophil derived human S100A12 (EN-RAGE) is strongly expressed during chronic active inflammatory bowel disease. Gut 2003; 52: 847-53.

38 Hollenbach E, Ruhl A, Zoller M et al. $\mathrm{T}$ cell activation by enteric glia: a novel pathway for the amplification of inflammatory responses in the enteric nervous system. Gastroenterology 2000; 118: A184.

39 Geboes K, Rutgeerts P, Ectors N et al. Major histocompatibility class II expression on the small intestinal nervous system in Crohn's disease.
Gastroenterology 1992; 103: 43947.

40 Adami C, Bianchi R, Pula G et al. S100B-stimulated NO production by BV-2 microglia is independent of RAGE transducing activity but dependent on RAGE extracellular domain. Biochim Biophys Acta 2004; 1742: 169-77.

41 Dionne S, Laberge S, Deslandres C et al. Modulation of cytokine release from colonic explants by bacterial antigens in inflammatory bowel disease. Clin Exp Immunol 2003; 133: 108-14. 